\title{
NUMERICAL ANALYSIS OF INFUSION STRATEGIES IN VACUUM ASSISTED RESIN TRANSFER MOLDING (VARTM) PROCESS
}

\author{
Himanshu V. Patel, Harshit K. Dave \\ Department of Mechanical Engineering, S. V. National Institute of Technology \\ Surat-395 007, India \\ Corresponding author: Harshit K. Dave, harshitkumar@yahoo.com
}

\begin{abstract}
The Liquid composite Molding (LCM) process, such as Vacuum Assisted Resin Transfer Molding (VARTM), offers a fast and high-quality production of composites laminates. In the VARTM process, the simulation tool is found beneficial to predict and solve composite manufacturing issues. The part quality is dependent on the resin mold filling stage in the VARTM process. The infiltration of resin into a porous fibrous medium is taken place during the resin mold filling stage. The permeability has a crucial role during the resin mold filling stage. In this study, simulation of resin infusion through multiple injection gates is discussed. The various infusion schemes are simulated to identify defect-free composite manufacturing. The simulation approach is applied to five different stacking sequences of reinforcements. In this transient simulation study, permeability and resin viscosity is essential inputs for the resin flow. The simulation approach found that a gating scheme plays a vital role in mold filling time and defect-free composite fabrication. It is found that the line gating system can be useful for fast mold filling over the point gating system.
\end{abstract}

Key words: VARTM, multiple injection gates, Permeability, Fiber Reinforced Composite, Resin Infusion, Process simulation

\section{INTRODUCTION}

Composite material is gaining attention from the last few decades because of its advanced material features such as specific weight and density ratio. Carbon fiber reinforced polymer (CFRP) is a synthetic composite material that is mostly employed in space applications. For the fabrication of composite material, various manufacturing processes are used, including hand layup, autoclave, and resin transfer molding (RTM). The Vacuum Assisted Resin Transfer Molding (VARTM) method has been widely employed in fabrication for decades since it is costeffective and dimensionally accurate (Patel and Dave, 2021). The resin inlet is selected based on the component size, length, and thickness, which are all process parameters. Since the last few decades, large composite components have been created using the VARTM method. Most failures are due to empty regions and unfilled areas, which motivated researchers to investigate flow monitoring (Yang et al., 2014).

Many researchers utilized both experimental and simulation strategies in their study. Simulation is significant since it offers an understanding of how a material will behave during fabrication. Correia et al. (2005) constructed an analytical formulation of the governing equations for incompressible fluid flow through compacting porous media and used them to composite fabrication using vacuum infusion. The influence of process variables, including input and outlet pressures, fiber structure, and layup sequence, was evaluated. Nedelcu and Carcea (2013) established a metal matrix-based mathematical model for multilayer composites. During the fabrication of multilayer composites, hydraulic pressure, reinforcement material, matrix type, fiber diameter, the mass ratio between reinforcement and composite masses, and mold temperature were all important factors. The ANSYS Fluent is an effective method for modelling resin flow that is simple to use and model (Patel et al., 2019).

Bayldon and Daniel (2009) developed a onedimensional model to study flow location and part thickness. The permeability of the fibrous media defines the mold filling. Permeability is an intrinsic property of fiber reinforcement that describes the ease with which fluid flows through the medium and includes all interactions between fibers and resin (Machado, 2016). Coulter and Guceri (1989) conducted experiments on resin impregnation in a thin three-dimensional carbon fiber reinforcement material that was fully monitored. They used boundary fitted coordinates and grid generation, as well as a Darcy's law-based stream function formulation. The permeability values were determined through experimentation using Darcy's equation. Kang et al. (2000) compared different injection methods with 
different gate positions and inlet pressures. For similar geometries, two types of multiple-gate injection systems were tested against single-gate injection. The effect of various injection pressures at various gates was also investigated, and it was discovered to be beneficial in reducing air entrapment and void formation. It was found that choosing an appropriate injection strategy could result in significant time savings in mold filling without compromising quality. Poodts et al., (2013) produced a model detailing a central injection scheme for a VARI process for building a ship runway. The cloth was impregnated using a central injection system. The inlet was placed in the middle of the runway, with a line runner running the length of the runway, and the outflow was placed all around the mold perimeter. Park and Kang (2003) conducted a parametric investigation of resin development and infusion time under various process conditions. In LCM operations, this can also be used to optimize gate locations in the transverse position for mold filling. Shojaei et al. (2003) studied how injection strategy affected the RTM process. For complex mold geometries, they explored sequential switching injection and simultaneous modified switching injection. They found that using multiple injection gates are the most viable approach to reduce mold filling time without compromise part quality. For the VARTM process, Nalla et al. (2007) created a multi-segment injection line. They discovered that this strategy is effective for feeding resin to different portions of the mold. They found that this method works well for parts with complex geometry and permeability fluctuation. Azlan et al. (2013) used two different infusion strategies to fabricate wind turbine blades. Other infusion techniques have resulted in a variety of flow front progression characteristics. They used Darcy's equation to anticipate filling time.

Joemon et al. (2021) carried out a numerical simulation and experimentation comparison. A control volume of specified dimensions is established in numerical modelling to replace the mold cavity in the experimental setup. The bi-directional E-glass fiber preform is assumed to be a porous structure. The experimentally obtained permeability value for different compaction pressures considered is given as an input to the numerical analysis, and the completion time of the process is forecasted. The numerical analysis uses the experimentally determined permeability value for the different compaction pressures evaluated, and the process completion time is predicted. Hancioglu et al. (2020) used an experimental and simulation approach to compare the VARTM and RTM processes. They kept track of the resin flow front and the time taken to fill the mold. They discovered that predicting the actual thickness distribution and volume of injected resin for component quality is not effective. Predicting the location of inlet and outlet gates and predicting flow patterns to avoid dry spot formation is the crucial aspect. The effects of vacuum pressure, input pressure, and mold temperature on the void content and volume fraction of polyester/e-glass fiber composites were investigated by Kedari et al., (2011). According to the experimental and analytical findings, a VARTM part with a high fiber volume fraction and low void content can be fabricated using a high mold temperature, high vacuum, and appropriately low inlet pressure. The flow parameters of VARTM during composite fabrication were examined by Kim et al. (2013). During the experiment, they used three different injection strategies. They discovered that the multi-directional injection method was the key to rapid mold filling.

The resin flow in the VARTM process was modelled using the ANSYS Fluent tool in this research article. For tracking the flow, the VOF model was used. As a process parameter, the resin infusion strategy based on inlet and outlet location has been selected. The simulation was carried out in a two-dimensional rectangle shape. In each injection strategy, the residual void area has been evaluated for five stacking sequences.

\section{MATERIALS AND METHOD}

\subsection{Materials}

Three types of reinforcing materials were employed to measure permeability in this study. Bidirectional reinforcement was utilized in composite manufacturing. As reinforcement materials, carbon, glass, and aramid fabrics were mimicked. Figure 1 illustrates a visual perspective of five stacking sequences. The fabric arrangement in the composite structure is shown in Table 1.

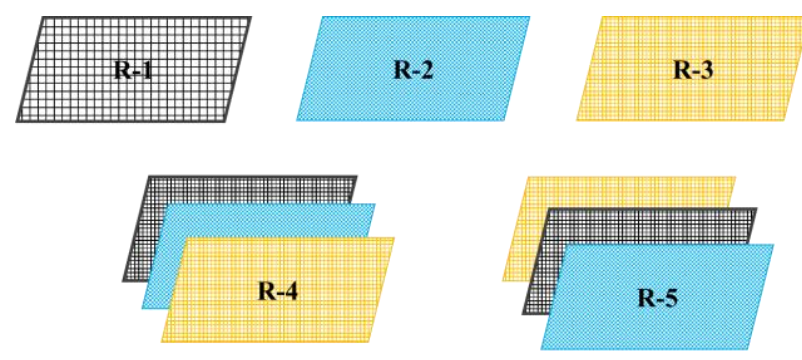

Fig.1. Stacking sequence of composite material

Table 1. Stacking sequences

\begin{tabular}{|l|c|c|}
\hline Sr. No. & Stacking sequence & Laminating structure \\
\hline \multicolumn{3}{|c|}{ Neat Specimen } \\
\hline R-1 & $\mathrm{C} 12$ & $\mathrm{C}_{1}-\mathrm{C}_{2} \ldots-\mathrm{C}_{12}$ \\
\hline R-2 & $\mathrm{G} 12$ & $\mathrm{G}_{1}-\mathrm{G}_{2} \ldots-\mathrm{G}_{12}$ \\
\hline R-3 & $\mathrm{A} 12$ & $\mathrm{~A}_{1}-\mathrm{A}_{2} \ldots-\mathrm{A}_{12}$ \\
\hline \multicolumn{3}{|c|}{ Hybrid Specimen } \\
\hline R-4 & $(\mathrm{CGA})_{4}$ & $\mathrm{CGA}-\mathrm{CGA}-\mathrm{CGA}-\mathrm{CGA}$ \\
\hline R-5 & $\left(\mathrm{C}_{2} \mathrm{G}_{2} \mathrm{~A}_{2}\right)_{2}$ & $\mathrm{C}_{2} \mathrm{G}_{2} \mathrm{~A}_{2}-\mathrm{C}_{2} \mathrm{G}_{2} \mathrm{~A}_{2}$ \\
\hline
\end{tabular}




\subsection{Methodology}

The simulation methodology is developed to lower the cost of selecting the best infusion strategy via trial and error. To simulate the VARTM process, an ANSYS fluent simulation model was developed. The resin flow through the porous media was represented as a two-phase (air/resin) fluid flow. Part geometry, resin viscosity, reinforcement permeability, and injection parameters of the infusion process all were required to be fed into the simulation tool.

For the VARTM process, Darcy's law that describes the relationship between flow rate, permeability, and fluid viscosity, is used to describe the flow of a fluid through a fibers preform as per equation 1 .

$$
\vec{V}=\frac{1}{\mu} \times[K] \nabla P
$$

Where $\vec{V}$ is the velocity of resin in porous medium, $[\mathrm{K}]$ permeability of the porous medium, $\mu$ viscosity of the resin, $\nabla P$ pressure gradient. Further, the pressure gradient is expressed with equation 2 .

$$
\nabla P=\frac{\Delta P}{L}
$$

Where $\Delta P$ the change in pressure and $\mathrm{L}$ is length up to flow front reached in the porous medium, injection pressure, vacuum pressure, capillary pressure, and gravity pressure comprise up the pressure $\Delta \mathrm{P}$. The influences of capillary pressure and vacuum pressure are dominant in the VARTM process. Equation (3) can be rewritten for one-dimensional flow as:

$$
\frac{d x}{d t}=\frac{K}{\mu \varepsilon} \frac{\Delta P(t)}{x(t)}
$$

Where $\mathrm{x}(\mathrm{t})$ is the flow front progression at time $\mathrm{t}$ and $\varepsilon$ is the porosity of the porous medium.

$$
\varepsilon=1-v_{f}
$$

Fiber volume fraction, $v_{f}$ can be expressed as

$$
v_{f}=\frac{W / \rho}{V}=\frac{n \cdot A \cdot \phi / \rho}{A \cdot h}=\frac{n \phi}{A \cdot h \cdot \rho}
$$

Where A.h is the total volume of the laminate and total weight of the laminate $\mathrm{W}=\mathrm{n}$.A. where, $\phi$ is the aerial density of reinforcement material, $\mathrm{n}$ is a number of layers.

The mold filling using the vacuum during infusion was simulated using a transient mode in ANSYS fluent. Figure 2 shows a flowchart of the simulation procedure. The volume of fluid (VoF) based simulation model was built using finite volume-based ANSYS Fluent tool.

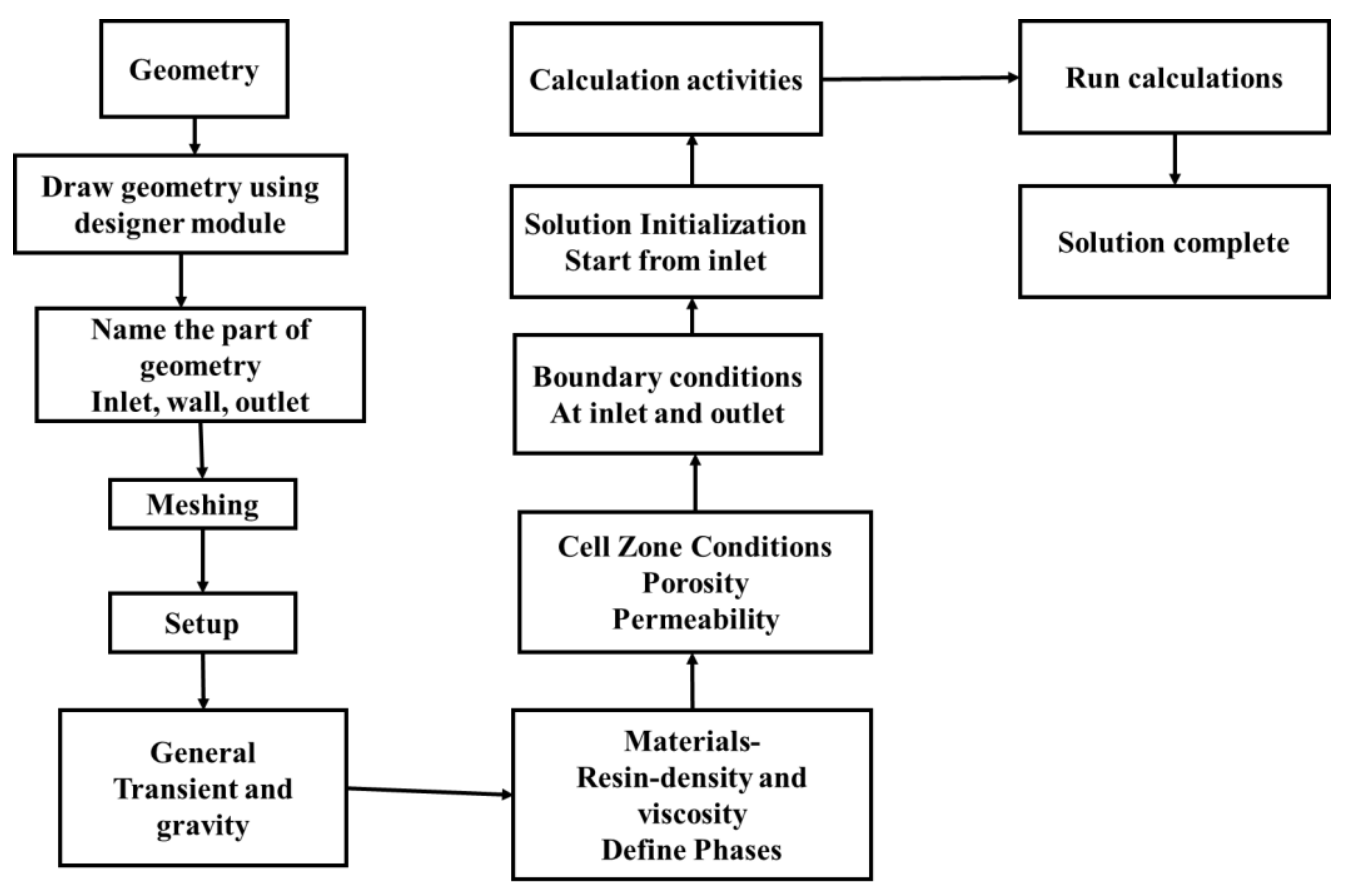

Fig. 2. Flowchart of the simulation procedure (Patel and Dave, 2021)

There are two phases in the VARTM simulation model: air and resin. Each cell zone would get the resin volume fraction $(f)$. When the $f$ is equal to zero, the cell is completely filled with air, and when $f$ is equal to one, the cell is completely filled with resin. The cell conditions applied to the geometry that shown in Figure 3. 


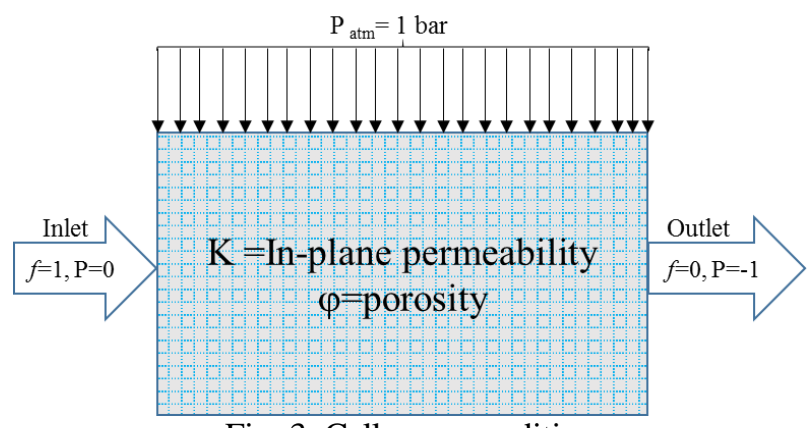

Fig. 3. Cell zone condition

\subsection{Infusion strategies}

The resin inlet and outlet positions influence the mold filling time. The gating position is divided into two categories: 1) line gating and 2) point gating. In a line gating system, point flow is transformed to line flow using a spiral wrap along with the reinforcement materials. Using an experimental approach to determine the effect of the gating system would be a costly solution. As a result, simulations based on the suggested technique is utilized to determine the optimal gating position for rapid and defect-free composite fabrication. Experiments would be used to validate the optimized gating system. The various gating strategies adopted in this approach is shown in Table 2 Simulation work was done on the following strategies to find the best gating strategy. Fig 4 shows a schematic view of each strategy. The simulation was performed on a rectangle geometry with $150 \mathrm{~mm}$ $\mathrm{x} 400 \mathrm{~mm}$ dimensions. The flow pattern and mold filling time for various stacking sequences were studied using the different point and line inlets and outlets.

Table 2. Infusion strategies

\begin{tabular}{|c|l|c|l|}
\hline $\begin{array}{c}\text { Sr. } \\
\text { No. }\end{array}$ & $\begin{array}{l}\text { Name of Infusion } \\
\text { Strategy }\end{array}$ & $\begin{array}{l}\text { Code } \\
\text { for } \\
\text { strategy }\end{array}$ & $\begin{array}{l}\text { No. of } \\
\text { inlet and } \\
\text { outlet }\end{array}$ \\
\hline 1 & Lengthwise infusion & I-1 & $\begin{array}{l}\text { Inlet=01; } \\
\text { outlet=01 }\end{array}$ \\
\hline 2 & Widthwise infusion & I-2 & $\begin{array}{l}\text { Inlet=01; } \\
\text { outlet=01 }\end{array}$ \\
\hline 3 & $\begin{array}{l}\text { Point infusion in } \\
\text { diagonal direction }\end{array}$ & I-3 & $\begin{array}{l}\text { Inlets=01; } \\
\text { outlet=01 }\end{array}$ \\
\hline 4 & All Directional infusion & I-4 & $\begin{array}{l}\text { Inlet=02; } \\
\text { outlets=02 }\end{array}$ \\
\hline 5 & $\begin{array}{l}\text { Point infusion in length } \\
\text { direction }\end{array}$ & I-5 & $\begin{array}{l}\text { Inlets=01; } \\
\text { outlets=01 }\end{array}$ \\
\hline 6 & $\begin{array}{l}\text { Point infusion in length } \\
\text { direction using multiple } \\
\text { outlet }\end{array}$ & $\begin{array}{l}\text { I-6 } \\
\text { outlet=02 }\end{array}$ \\
\hline 7 & $\begin{array}{l}\text { Point infusion in length } \\
\text { inlet }\end{array}$ & I-7 & $\begin{array}{l}\text { Inlet=01; } \\
\text { outlet=02 }\end{array}$ \\
\hline
\end{tabular}

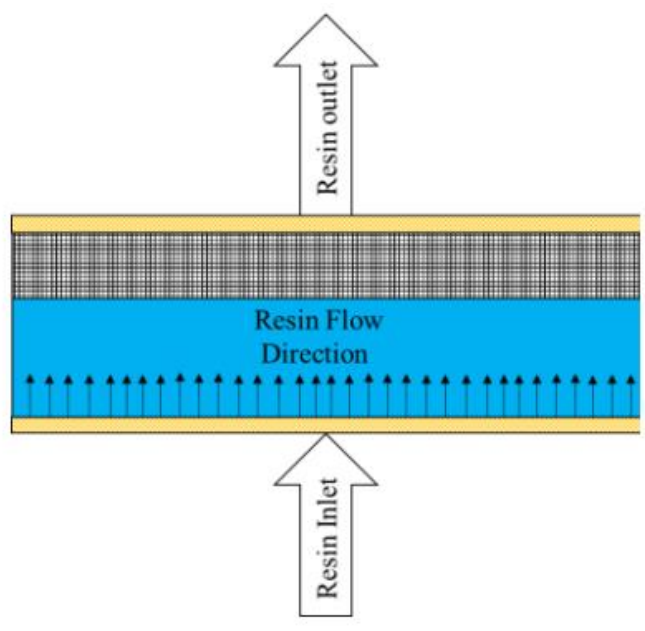

(a) Widthwise infusion

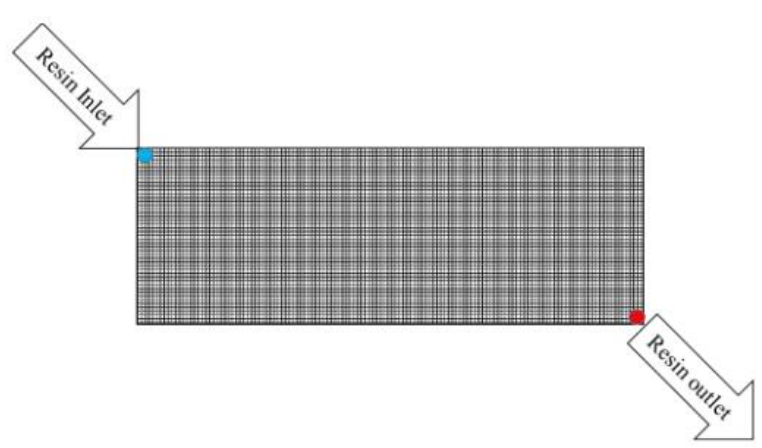

(b) Diagonal infusion

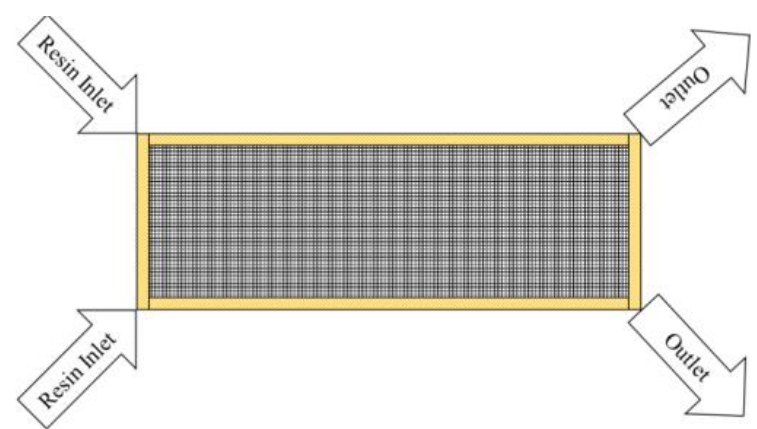

(c) All Directional infusion

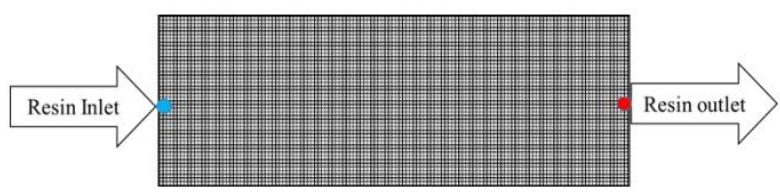

(d) Point infusion in a length direction

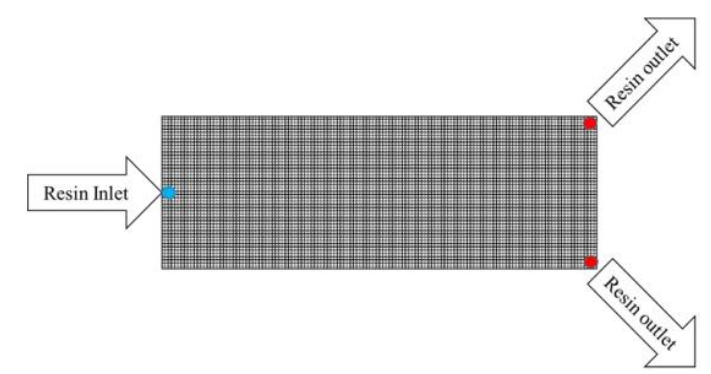

(e) Multiple outlets 


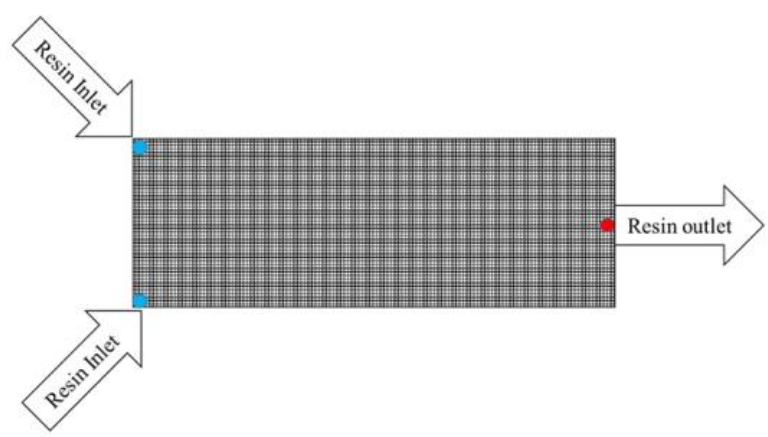

(f) Multiple Inlets

Fig. 4. Various Infusion strategies

\section{RESULTS AND DISCUSSION}

The Table 3 represents the mold filling time for different infusion strategies for different stacking sequences. The calculated value of the permeability was used as an input of the simulation.

Table 3. Mold filling time comparison with infusion strategy for different stacking sequences

\begin{tabular}{|c|l|c|c|c|c|c|}
\hline \multirow{2}{*}{$\begin{array}{l}\text { Sr. } \\
\text { No. }\end{array}$} & \multirow{2}{*}{\begin{tabular}{c}
\multirow{2}{*}{$\begin{array}{l}\text { Infusion } \\
\text { Strategy }\end{array}$} \\
\cline { 3 - 7 }
\end{tabular}} & \multicolumn{5}{|c|}{$\begin{array}{c}\text { For Different stacking } \\
\text { sequences mold filling } \\
\text { time(s) }\end{array}$} \\
\cline { 2 - 7 } & R-1 & R-2 & R-3 & R-4 & R-5 \\
\hline I-2 & $\begin{array}{l}\text { Length Wise } \\
\text { Infusion }\end{array}$ & 120 & 240 & 135 & 102 & 90 \\
& $\begin{array}{l}\text { Width wise } \\
\text { infusion }\end{array}$ & 23 & 35 & 25 & 28 & 15 \\
\hline I-3 & $\begin{array}{l}\text { Point infusion in } \\
\text { diagonal direction }\end{array}$ & 210 & 485 & 270 & 295 & 250 \\
\hline I-4 & $\begin{array}{l}\text { All directional } \\
\text { Infusion }\end{array}$ & 165 & 295 & 190 & 205 & 120 \\
\hline I-5 & $\begin{array}{l}\text { Point infusion in } \\
\text { length direction }\end{array}$ & 195 & 370 & 215 & 230 & 175 \\
\hline I-6 & $\begin{array}{l}\text { Point infusion in } \\
\text { length direction } \\
\text { using multiple } \\
\text { outlet }\end{array}$ & 180 & 350 & 220 & 230 & 150 \\
\hline I-7 & $\begin{array}{l}\text { Point infusion in } \\
\text { length direction } \\
\text { using multiple inlet }\end{array}$ & 180 & 315 & 190 & 205 & 135 \\
\hline
\end{tabular}

Figure 5 shows the simulated results for various infusion strategies. For the same reinforcement, there is a wide range of flow progression. One of the most important input factors in a mold filling simulation is the permeability of the preform. It assesses the resin resistance to flow in the medium. The weaving pattern and fiber volume percentage of the preform determine the permeability. An experimentation approach was used to determine permeability, fiber volume fraction, and viscosity. (Patel and Dave, 2021).

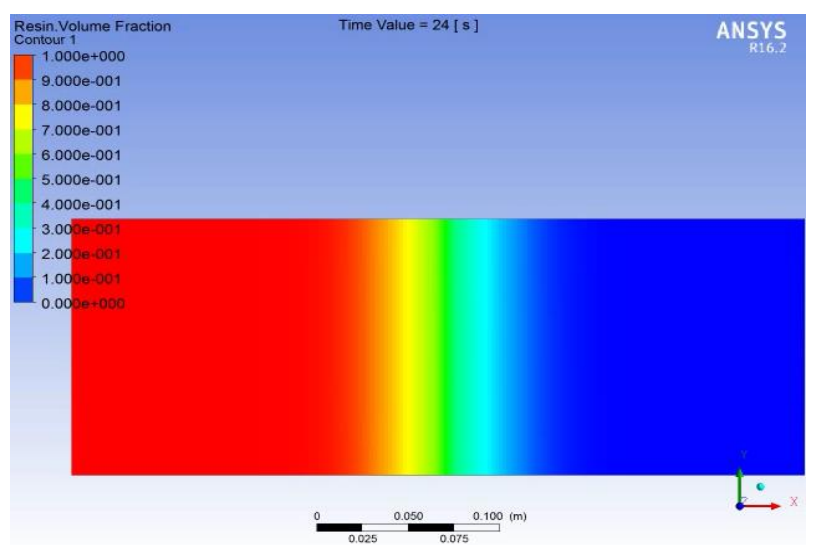

(a) I-1, Mold filling time $t_{m}=120 \mathrm{~s}$

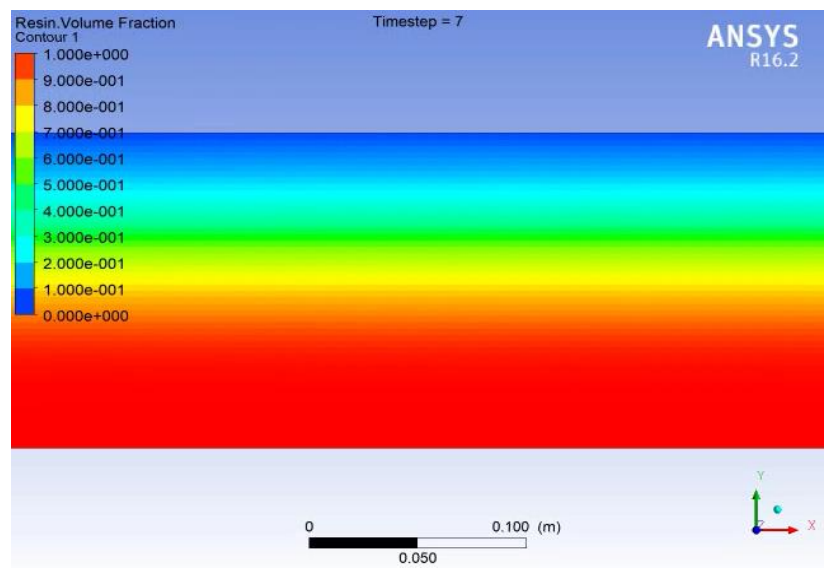

(b) I-2, Mold filling time $t_{m}=23 \mathrm{~s}$

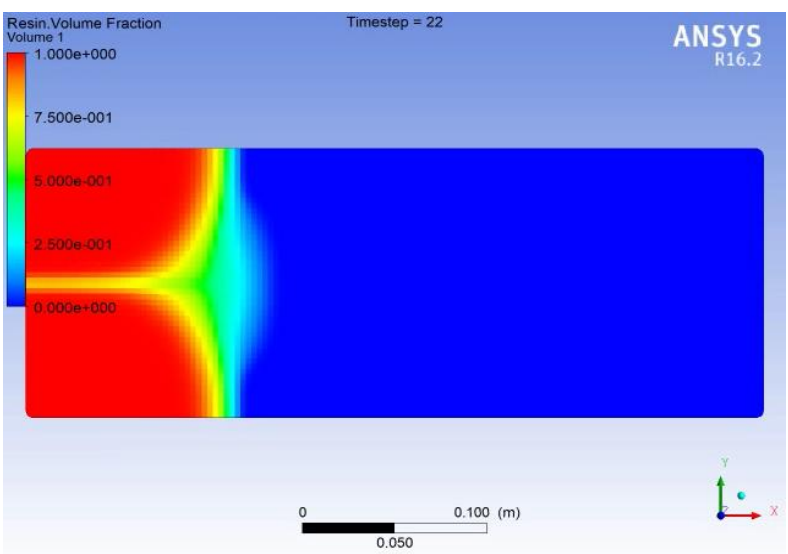

(c) I-4, Mold filling time $t_{m}=165 \mathrm{~s}$

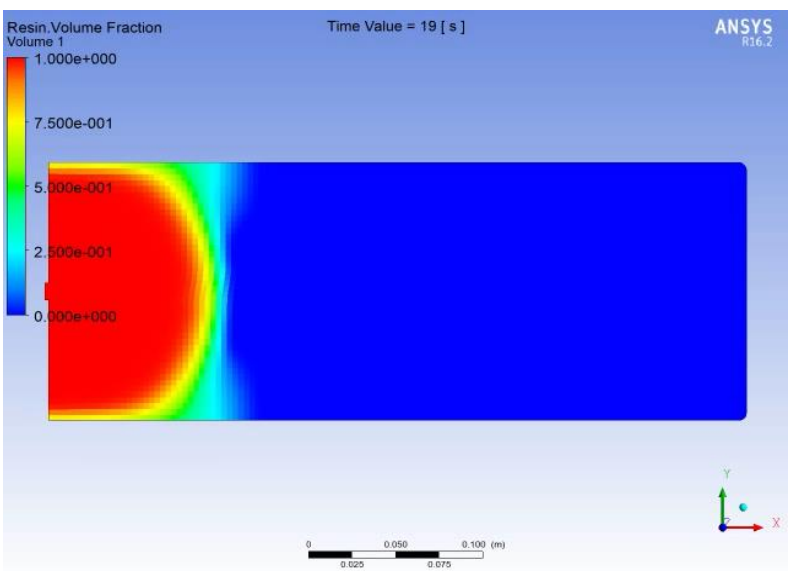

(d) I-6, Mold filling time $t_{m}=180 \mathrm{~s}$ 


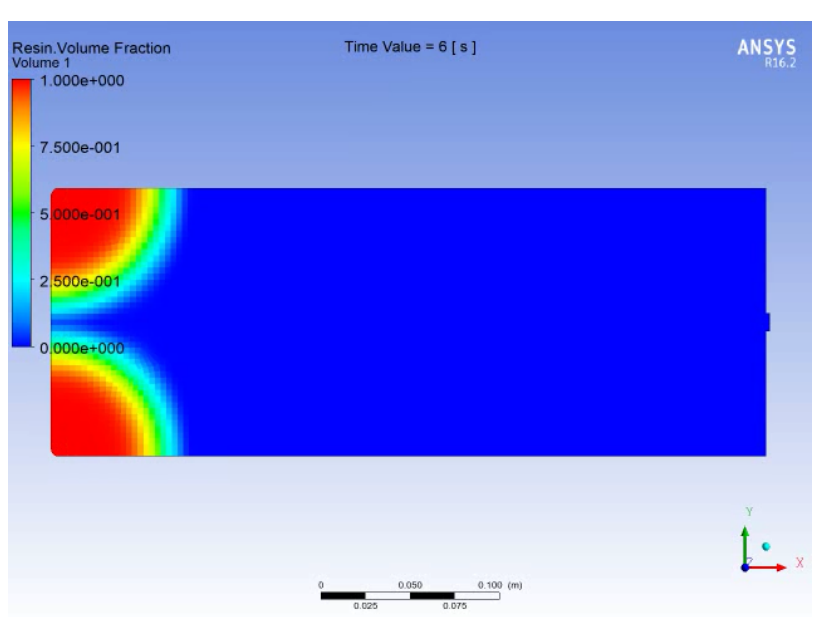

(e) I-7, Mold filling time $t_{m}=180 \mathrm{~s}$

Fig. 5. Flow comparisons

Flow comparison for all infusion strategies is shown in Figure 5. The I-2 technique, i.e. width wise infusion method, had the fastest mold filling time of all the infusion strategies. It can be seen that the I-2 strategy has the fastest flow in the width direction among all the infusion strategies. The fabrication of turbine blades could benefit from this type of infusion strategy. However, there were multiple inlets and outlets, but it can be seen that direct line flow progresses faster than point flow. The comparison between diagonal infusion, all-directional infusion, and point infusion using the central inlet and outlet is shown in Figure 6. In the I-4 strategy, the central inlet contours the resin towards the outlet, resulting in a completely resin-rich composite laminate at the outlet end. Multiple outlets suction resin faster towards the end of the I-6 strategy. However, because of the diagonal positioning of outlets, some areas go dry. The flow front colliding causes air trapping and the formation of a dry spot. Although extra resin was supplied, it can be noticed that the diagonal strategy allows the resin to reach the entire mold, but the opposite corner of the inlet remains dry. This type of strategy is useful for avoiding dry areas during the infusion of complicated components.

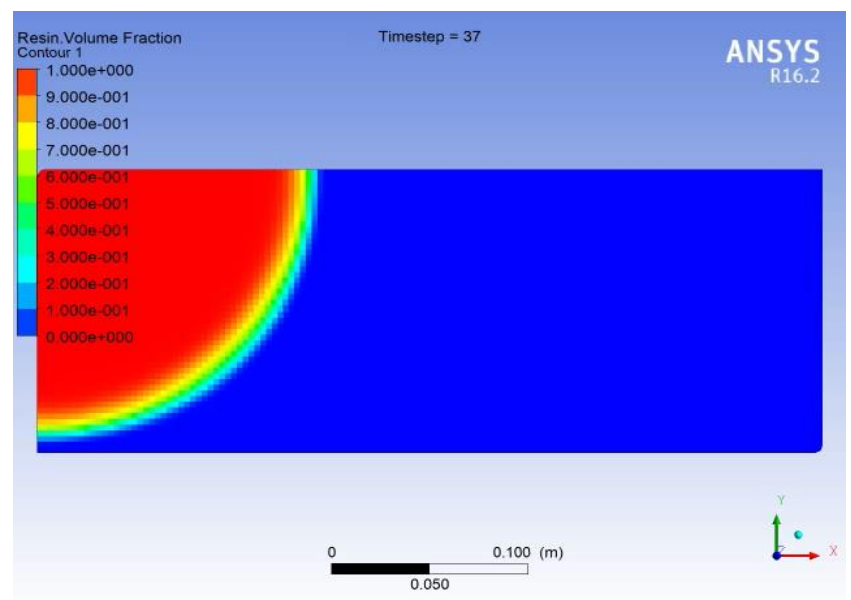

(a) I-3, Mold filling time $t_{m}=23 \mathrm{~s}$

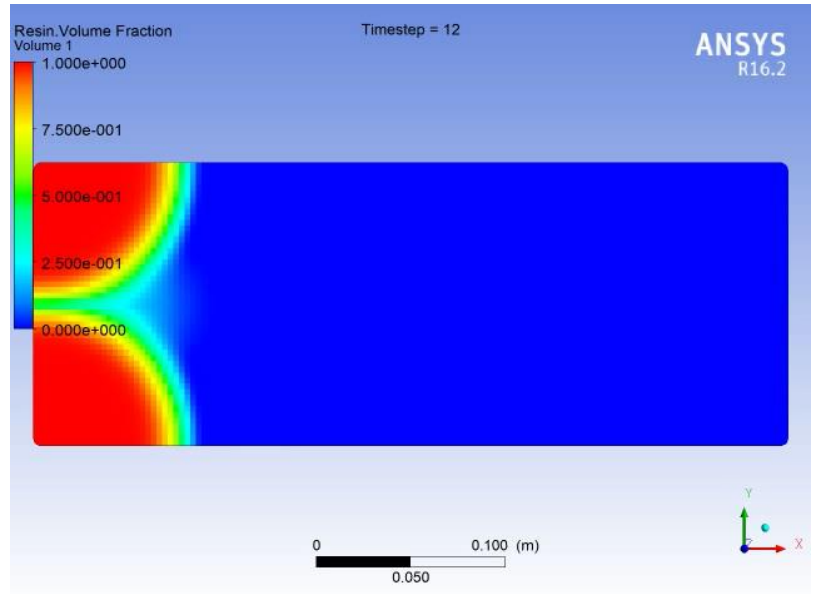

(b) I-4, Mold filling time $\mathrm{t}_{\mathrm{m}}=165 \mathrm{~s}$

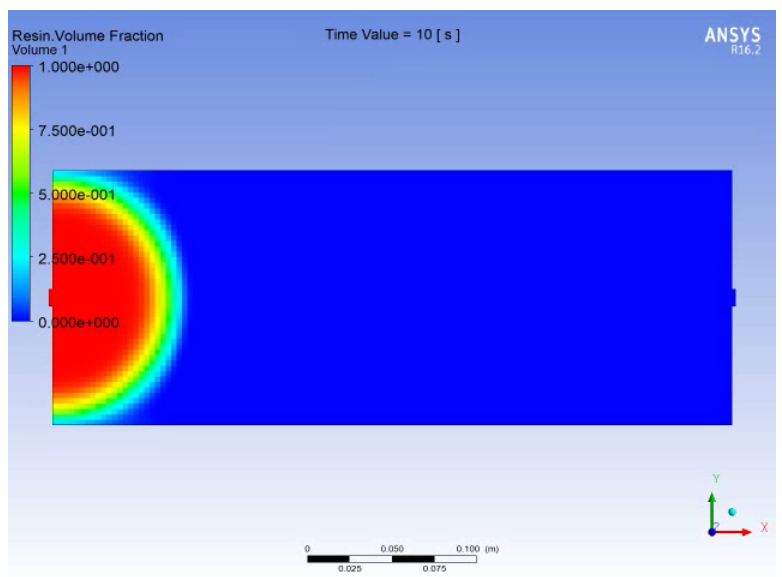

(c) I-5, Mold filling time $t_{m}=195 \mathrm{~s}$

Fig. 6. Flow comparisons

The improper inlet and outlet locations induce the flow defects that can be observed during the resin flow simulations. In each strategy, the resin inlet becomes a resin-rich zone, while the outlet is located away from the inlet, resulting in a dry spot region at the outlet end. The most common cause of poor component composite manufacturing using resin infusion is the formation of dry spots. In the I-4 strategy, it can be seen that the resin flow fronts are colliding. Due to the collision of two flow fronts, the air became trapped in that area, resulting in the formation of a dry spot. Figure 7 shows the various defects during the flow progression. These defects may arise due to improper location of inlet and outlet during the multi-gating resin infusion. Within Resin Infusion parts, both voids and dry spots are unsaturated preform regions. The two defects, however, can be identified by their sizes. Dry spots can range in size from a few millimeters to $60 \%$ of the composite part size and are commonly found by visual inspection. Furthermore, the development of dry spots usually results in the rejection of the manufactured composite component (Hamidi and Altan, 2017). Multiple injection gates are widely used to reduce a mold-filling time for large parts with 
complex geometry. As a result, many flow fronts wet the preform at the same time. If the position of inlets is not appropriately designed, the merging of flow
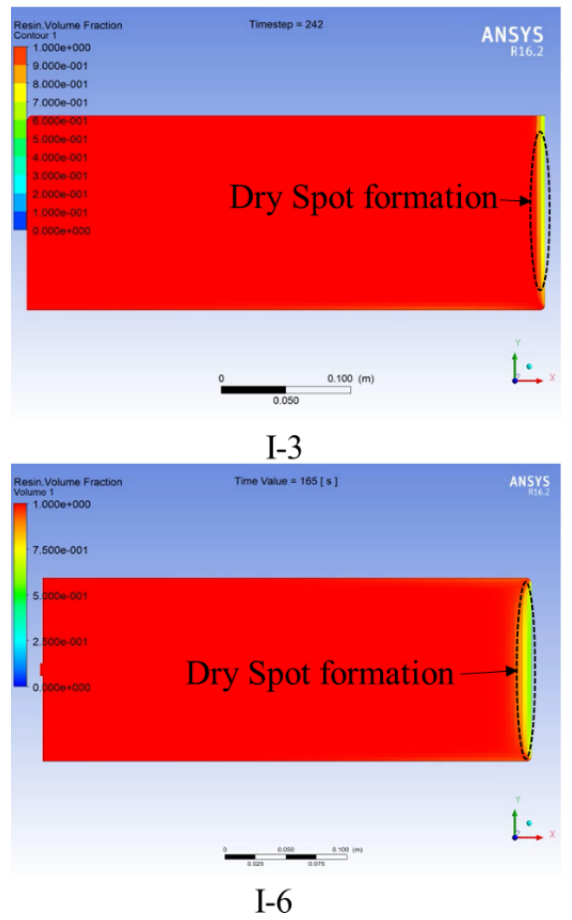

fronts can result in air entrapment in large areas (Yang et al., 2010). Other simulation viz. I-1, I-2, and I-5 found effective and minor defects were observed.
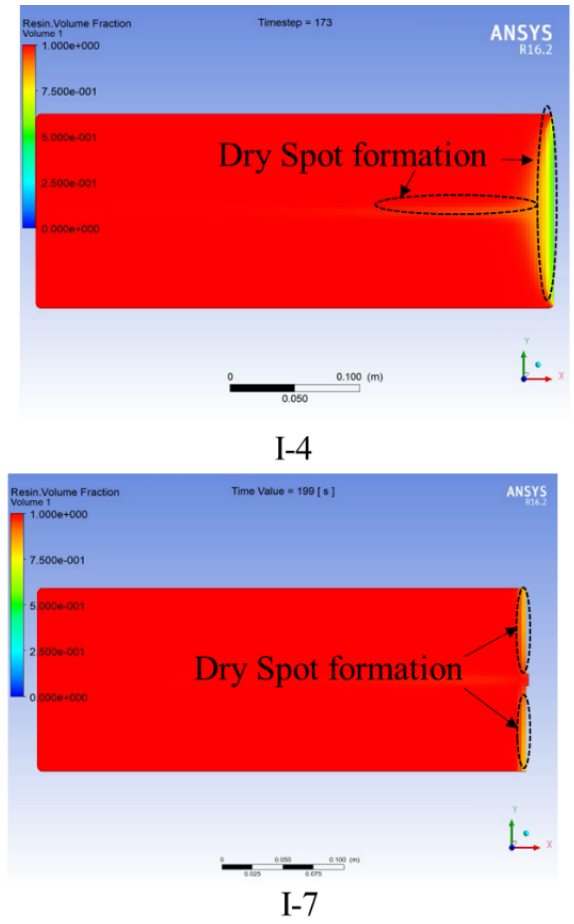

Fig. 7. Defects in Multi-gating

When resin reaches at the outlet end before the preform is entirely impregnated, dry spots appear. The resin front reached the outlet vent before the preform was completely wet because the flow along the sides of the preform was significantly faster than the impregnating flow in the centre.

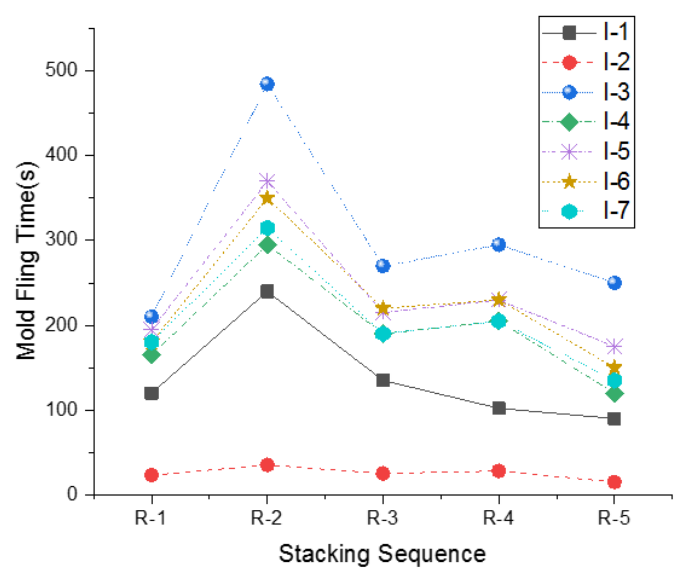

Fig. 8. Mold filling Vs Stacking Sequence

Figure 8 shows the variation in mold filling time for various stacking sequences. Due to its fine construction, R-2 reinforcement takes a long time to fill the mold. Fine architecture of the fabric creates micro pores, that increases fluid resistance. Mold filling time is also increased as a result of the higher fluid resistance. Permeability is the term used to describe fluid resistance.

\section{CONCLUSIONS}

Flow simulation for Polymer Matrix Composite (PMC) fabrication utilizing the VARTM technique with varied stacking sequences is performed in this study. The flow of resin was observed during the simulation. Experimental permeability and porosity were used as inputs in the simulation of the flow front. The following conclusions can be made from the above investigation:

1) Length-wise resin flow is common; however, it is not a cost-effective option for long components like turbine blades due to geometry changes. For such features, widthwise flow is more efficient, faster mold filling.

2) A point inlet takes more time than a line inlet. The flow inlet progresses on the surface level first and then through the thickness, which takes more time.

3) Flow front collision is the most likely cause of the dry spot and void formation during the resin infusion process.

4) Various process parameters, such as fiber volume fraction, resin injection applied vacuum level, fiber architecture, injection and ventilation gate location, resin viscosity, and molding temperature, are found effective for the quality of the resulting composite parts in a simulation of the resin infusion process. 


\section{REFERENCES}

1. Bayldon, J.M. and Daniel, I.M., (2009) Flow modeling of the VARTM process including progressive saturation effects. Compos. Part A Appl. Sci. Manuf., 40(8), 1044-1052.

2. Correia, N.C., Robitaille, F., Long, A.C., Rudd, C.D., Šimáček, P. and Advani, S.G., (2005) Analysis of the vacuum infusion molding process: I. Analytical formulation. Compos. Part A Appl. Sci. Manuf., 36(12), 1645-1656.

3. Coulter, J.P. and Güçeri, S.I., (1989) Resin impregnation during composites manufacturing: theory and experimentation. Compos Sci Technol, 35(4), 317-330.

4. Hamidi, Y.K. and Altan, M.C., (2017) Process induced defects in liquid molding processes of composites. International Polymer Processing, 32(5), 527-544.

5. Hancioglu, M., Sozer, E.M. and Advani, S.G., (2020) Comparison of in-plane resin transfer molding and vacuum-assisted resin transfer molding' effective'permeabilities based on mold filling experiments and simulations. J. Reinf. Plast. Compos., 39(1-2), 31-44.

6. Joemon, R.S., Tojo, J., Abraham, P.G., Nair, S.S., George, N. and Rathish, T.R., (2021) Numerical investigation of VARTM process using finite volume method. Mater. Today: proc., 46, 590-593.

7. Kang, M.K., Jung, J.J. and Lee, W.I., (2000) Analysis of resin transfer moulding process with controlled multiple gates resin injection. Compos. Part A Appl. Sci. Manuf., 31(5), 407-422.

8. Kedari, V.R., Farah, B.I. and Hsiao, K.T., (2011) Effects of vacuum pressure, inlet pressure, and mold temperature on the void content, volume fraction of polyester/e-glass fiber composites manufactured with VARTM process. J. Compos. Mater., 45(26), 27272742.

9. Kim, Y.H., Lee, J.W. and Park, J.M., (2013) Flow Characteristics of Vacuum Assisted Resin Transfer Molding Process Depending on the Capillary Phenomenon. Mater. Sci. Forum, 762, 612-620 Trans Tech Publications Ltd.

10.Machado, J.M.E., (2016) Manufacturing Processes for the Development of Unmanned Vehicles.

11.Mohd Azlan, M.A., Abdul Latif, M.R., Abdullah, M.Z., Zainal Abidin, K.A. and Wahab, A.A., (2013) Flow behavior in the resin infusion of glass fiber reinforced polymer wind turbine blade. J. Adv. Mater. Res., 686, 118-124, Trans Tech Publications Ltd.

12.Nalla, A.R., Fuqua, M., Glancey, J. and Lelievre, B., 2007. A multi-segment injection line and real-time adaptive, model-based controller for vacuum assisted resin transfer molding. Compos. Part A Appl. Sci. Manuf., 38(3), pp.1058-1069.

13.Nedelcu, D., Carcea, I. (2013). Technology for obtaining samples of layered composite materials with metallic matrix, Met. Mater. Int., 19(1), 105112.

14.Park, J. and Kang, M.K., (2003) A numerical simulation of the resin film infusion process. Compos. Struct, 60(4), 431-437.

15.Patel, H.V. and Dave, H.K., (2021). An experimental and simulation-based analysis of resin flow front during fabrication of lightweight composite components using VARTM process. Int. J. Mater. Eng. Innov., 12(2), 149-164.

16.Patel, P., Gajjar, T., Shah, D., Joshi, S. and Mawandiya, B.K., (2020) September. Numerical study of resin flow in VARTM composite manufacturing process. In Technologies for Sustainable Development: Proceedings of the 7th Nirma University International Conference on Engineering (NUiCONE 2019), November 21-22, 2019, Ahmedabad, India, 344-350 CRC Press.

17.Poodts, E., Minak, G., Dolcini, E. and Donati, L., (2013) FE analysis and production experience of a sandwich structure component manufactured by means of vacuum assisted resin infusion process. Compos. B. Eng., 53,179-186.

18.Shojaei, A., Ghaffarian, S.R. and Karimian, S.M.H., (2003) Numerical analysis of controlled injection strategies in resin transfer molding. J Compos Mater., 37(11), 1011-1035.

19. Yang, B., Jin, T., Bi, F. and Li, J., (2014). Modeling the resin flow and numerical simulation of the filling stage for vacuum-assisted resin infusion process. J. Reinf. Plast. Compos, 33(21), 1976-1992. 20. Yang, J., Jia, Y., Ding, Y., He, H., Shi, T. and An, L., (2010) Edge effect in RTM processes under constant pressure injection conditions. J. Appl. Polym. Sci., 118(2), 1014-1019.

Received: March 16, 2021 / Accepted: December 20, 2021 / Paper available online: December 25, 2021 (C) International Journal of Modern Manufacturing Technologies 